\title{
Faces do catolicismo
}

\section{brasileiro}

\section{contemporâneo}

FAUSTINO TEIXEIRA

\section{FAUSTINO TEIXEIRA}

é professor adjunto no Programa de

Pós-Graduação em

Ciência da Religião

da Universidade

Federal de Juiz de

Fora, pesquisador do

CNPq e consultor do

Iser/Assessoria (Rio

de Janeiro). É autor

de, entre outros, Os

Encontros Intereclesiais

de CEBs no Brasil

(Paulinas). 
Por motivos editoriais, as notas estão no final do artigo.

\section{"Quero punhado}

dessas, me

\section{defendendo em}

Deus, reunidas de mim em volta..."

\section{(Guimarães Rosa).}

Com base dos dados do Censo de 2000, realizado pelo IBGE, o catolicismo continua sendo a religião majoritária do Brasil, envolvendo cerca de I 25 milhões de membros, ou seja, três quartos da população brasileira (73,8\%). Mas se os números absolutos mostram essa presença massiva, o olhar atento sobre os censos brasileiros, sobretudo a partir da segunda metade do século passado, já revela uma progressiva redução de membros. Em sua clássica análise dos censos de 1940, 1950 e 1960, Cândido Procópio Camargo já havia pontuado essa "tendência geral para um declínio moderado, mas constante, de adeptos da Igreja Católica" ( I ). Mas foi sobretudo a partir dos anos 80 que a porcentagem de católicos foi declinando cada vez mais: 90\% em I980, 83,3\% em I99। e 73,8\% em 2000. Entre os dois últimos censos ( 199 | e 2000) a população católica cresceu um pouco mais de três milhões, e continua crescendo, mas em taxas bem inferiores às do crescimento populacional. Esse aumento "esconde, 
na realidade, um diferencial negativo de 16 milhões, se o crescimento dos católicos tivesse se dado no mesmo ritmo que o da população brasileira, ao longo desse período" (2).

O Censo de 2000 não apenas revela fissuras na tradicional hegemonia católica, mas indica também o crescimento dos evangélicos e dos "sem religião", que alcançaram, respectivamente, índices de $15,4 \%$ e 7,3\% da população brasileira. Mas vale ressaltar que o crescimento evangélico deve-se sobretudo à expansão pentecostal, que responde sozinha por $10,4 \%$ do percentual evangélico. É correto falar, como Pierre Sanchis, que a Igreja Católica “está perdendo o seu caráter de definidor hegemônico da verdade e da identidade institucional no campo religioso brasileiro" (3). É também pertinente reconhecer que há hoje no Brasil o início de um processo de diversificação religiosa, mas que ainda não é assim tão

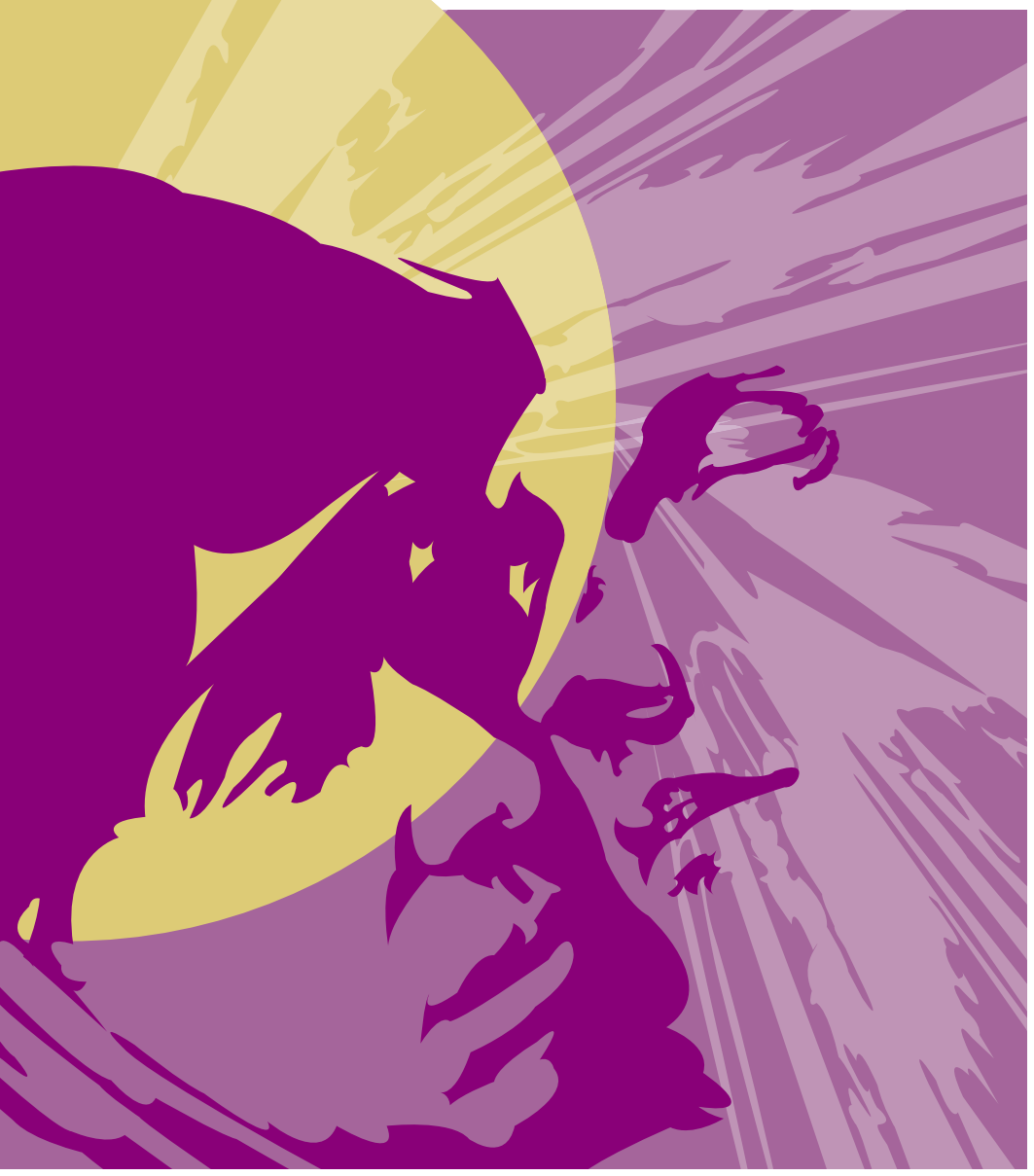

amplo como certas análises dão a entender. Os dados do último censo dão razão a Antônio Flávio Pierucci quando contesta a pretensa e ampla diversidade religiosa no Brasil. Na verdade, a soma da declaração de crença dos católicos e evangélicos nesse censo beira os $90 \%$. Com a exclusão daqueles que se declaram "sem religião", a diversidade religiosa fica concentrada em 3,5\% da população brasileira. Para Pierucci, é o "espectro do monoteísmo" que ainda predomina no Brasil, com todos os seus desdobramentos exclusivistas (4). Mas já se começa a apontar para uma situação nova, marcada pela “destradicionalização" e pela pluralização do campo religioso.

\section{A COMPLEXIDADE DO CAMPO RELIGIOSO CATÓLICO}

O catolicismo no Brasil revela uma grande complexidade. Trata-se de um campo religioso caracterizado por grande diversidade. A pluralidade é um traço constitutivo de sua configuração no Brasil. Na lúcida visão de Pierre Sanchis, o modo como se firma a identidade católica no país envolve "mecanismos de fagocitose" bem peculiares, que traduzem uma roupagem singularmente plural: "há religiões demais nesta religião" (5). Impressiona também a capacidade de adaptação e ajustamento dessa religião às novas situações: “quando observada de perto, vemos como ela se abre e se permite diversificar, de modo a oferecer, em seu interior, quase todos os estilos de crença e de prática da fé existentes também fora do catolicismo" (6). Os diversos censos realizados no Brasil não conseguem captar essa plasticidade religiosa, e muito menos a realidade cada vez mais presente do trânsito religioso ou da dupla (ou tripla) pertença religiosa. Indaga-se sobre a a identidade religiosa do informante, mas deixa-se escapar suas práticas e crenças (7). No caso do catolicismo, constata-se que o número de praticantes, ao contrário da tradição protestante, é reduzido se compa- 
rado com a grande massa dos católicos, que mantêm "frouxos vínculos nominais" com sua tradição religiosa. Na visão de Carlos Brandão, ao contrário do fiel protestante, que "precisa ser para participar", o fiel católico pode muito bem "participar sem ser", ou participar a seu modo num quadro amplo e plural de maneiras de exercer sua vinculação (8).

Aplasticidade dos modos de ser católico no Brasil é expressão de uma genuinidade brasileira, caracterizada pela grande ampliação das possibilidades de comunicação com o sagrado ou com o "outro mundo". O que para o protestante tradicional ou católico romanizado seria expressão de pernicioso sincretismo ou superstição, para boa parte dos fiéis significa um modo de alargar as "possibilidades de proteção" (9). É como expressa o personagem de Guimarães Rosa, no livro Grande Sertão: Veredas: "Muita religião, seu moço! Eu cá, não perco ocasião de religião. Aproveito de todas. Bebo água de todo rio... Uma só, para mim é pouca, talvez não me chegue [...]. Tudo me quieta, me suspende. Qualquer sombrinha me refresca" (10).

\section{AS MALHAS DO CATOLICISMO}

Não dá para situar o catolicismo brasileiro num quadro de homogeneidade. $\mathrm{Na}$ verdade, existem muitos "estilos culturais de "ser católico", como vêm mostrando os estudiosos que se debruçam sobre esse fenômeno. São malhas diversificadas de um catolicismo, ou se poderia mesmo falar em catolicismos. Há um catolicismo "santorial", um catolicismo "erudito ou oficial", um catolicismo dos "reafiliados", marcado pela inserção num " "regime forte' de intensidade religiosa" (CEBs, RCC) e um emergencial catolicismo midiático. Não se trata de realidades estanques e cristalizadas, mas inserem-se num quadro geral marcado por relações de comunicação, de proximidades, tensões e distanciamentos.

O catolicismo santorial (11), para usar uma expressão de Cândido Procópio Ca-

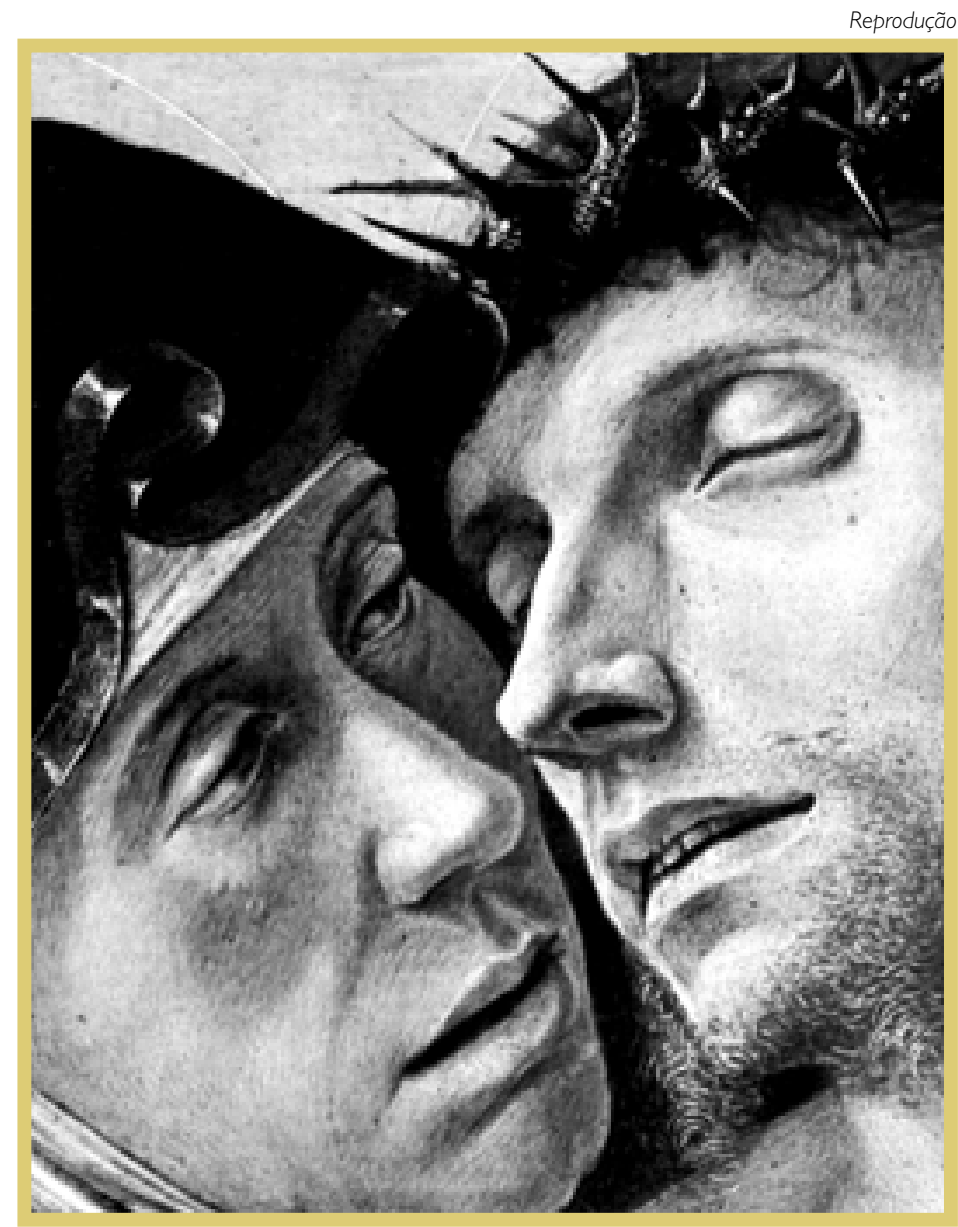

margo, é uma das formas mais tradicionais de catolicismo presentes no Brasil desde o período da colonização. Tem como característica central o culto aos santos. Foi esse culto que marcou a peculiar dinâmica religiosa brasileira, de caráter predominantemente leigo, seja nas confrarias e irmandades, seja nos oratórios, capelas de beira de estrada e santuários. $\mathrm{O}$ catolicismo brasileiro foi durante muito tempo um catolicismo de "muita reza e pouca missa, muito santo e pouco padre". Os santos sempre ocuparam um lugar de destaque na vida do povo, manifestando a presença de um "poder" especial e sobre-humano, que penetra nos diversos espaços de vida e favorece, numa estreita aproximação e familiaridade com seus devotos, a proteção diante das incertezas da vida:

"Os santos penetram na vida dos que os veneram, misturando-se com seus problemas, suas necessidades mais urgentes, nos
Detalhe do quadro Pietá, de Giovanni Bellini 
negócios, na vida familiar, nos casamentos, nos amores. E tudo isto, sem cerimônia, sem se precisar de apresentação, sem intermediário. Tudo se passa entre o santo e seu devoto. Uma certa intimidade até, sem implicar desrespeito, mas intimidade que chega até mesmo à imposição de certas punições, como santo de cabeça para baixo, santo fora de sua capela, santo voltado para as paredes" (12).

Esse catolicismo das devoções populares mantinha uma relativa autonomia com respeito ao catolicismo institucional. Não havia uma oposição aos padres, e quando estes apareciam - por ocasião das desobrigas ou missões populares - eram acolhidos e festejados. Mas a dinâmica dessa religiosidade "dispensava" a presença dos representantes oficiais da igreja, gozando, assim, de ampla liberdade. Como mostrou Carlos Brandão, em determinadas ocasiões o povo "ocupava padre”, para certas bênçãos ou rituais de passagem, mas o resto da vida de fé ficava mesmo por conta dos "recursos miúdos dos objetos simbólicos de fé" dos agentes religiosos populares (13). É um catolicismo que "quase chega a constituir-se um párasistema religioso setorialmente autônomo frente a uma Igreja de que ele sempre se reconhece parte" (14).

Foi esse catolicismo do povo que sofreu o embate violento da assim chamada "romanização", que marcou o processo de instauração no Brasil de um "catolicismo universalista”, caracterizado pelo maior controle sobre os leigos e suas associações e de adequação do catolicismo brasileiro às diretrizes centralizadoras de Roma. Mas, como mostrou Pedro Ribeiro de Oliveira, “o processo de romanização foi forte, bastante para combater o catolicimo popular, mas não o suficiente para implantar a forma romana na grande massa dos católicos" (15). Não há como negar o impacto da romanização sobre a forma tradicional da vida religiosa, mas as concepções basilares do catolicismo popular tradicional, como o culto aos santos e a crença nos milagres, permanecem vivas. E além disso há uma incorporação original por parte do povo de traços da romaniza- ção, o que evidencia "o aspecto dinâmico e criativo do catolicismo popular que se refaz continuamente" (16).

O fato de a Região Nordeste do Brasil despontar no Censo de 2000 como a mais católica revela algo da força e presença da tradição do catolicismo santorial (17). Importantes estudos na área de antropologia mostraram com vigor a coerência, complexidade e diversidade desse catolicismo, que não pode ser apressadamente identificado como um aglomerado de superstições ou crendices. E, além do mais, vem animado por impressionante poder de penetração e reprodução nos meios populares (18). No caso específico do Nordeste, há sem dúvida o influxo da presença de figuras do clero popular, como padre Cícero e frei Damião. Mas o que é importante sublinhar aqui é a força e o enraizamento de uma "teia de símbolos e valores católicos tradicionais" em determinadas regiões que tem exercido, na prática, uma forte resistência à penetração de outras experiências religiosas, em particular das tradições pentecostais (19).

O catolicismo oficial, como outras instituições religiosas tradicionais, encontra-se num momento de crise e declínio. É algo que se relaciona com a progressiva afirmação de uma "sociedade pós-tradicional", que coloca em questão a forma usual de preservação da tradição e exige processos criativos de sua reinvenção e inserção no tempo. Há hoje em dia nas instituições tradicionais uma "desregulação" identitária e uma grande dificuldade de transmissão regular dos valores religiosos de uma geração para outra. Deixa-se de assegurar a afirmação de uma memória coletiva, o que ocorria de forma garantida nas sociedades tradicionais (20). Instaura-se, assim, uma crise na "construção individual da continuidade crente". Uma crise que se traduz pelo progressivo enfraquecimento da figura do praticante regular, em geral associada a comunidades de sentido fortemente constituídas, em favor da irrupção da figura do peregrino, que traz consigo as marcas da mobilidade construída a partir de experiências pessoais (21). Como mostrou Antônio Flávio Pierucci, 
“[...]nas sociedades pós-tradicionais, et pour cause, decaem as filiações tradicionais. Nelas os indivíduos tendem a se desencaixar de seus antigos laços, por mais confortáveis que antes pudessem parecer. Desencadeiase nelas um processo de desfiliação em que as pertenças sociais e culturais dos indivíduos, inclusive as religiosas, tornam-se opcionais e, mais que isso, revisáveis, e os vínculos, quase só experimentais, de baixa consistência. Sofrem fatalmente com isso, as religiões tradicionais" (22).

Os últimos censos realizados no Brasil revelam claramente esse enfraquecimento ou mesmo declínio da figura do praticante católico. Fala-se hoje no catolicismo como "doador universal", na medida em que "tornou-se o principal celeiro no qual outros credos arregimentam adeptos" (23). Em sintonia com a conjuntura eclesiástica internacional, marcada pela ênfase no anúncio explícito, o bloco do catolicismo institucional no Brasil vem apostando na reinstitucionalização ou recatolização, com campanhas bem precisas na linha de uma melhor internalização dos valores religiosos instituídos. Pode-se registrar o atual projeto nacional de evangelização promovido pela CNBB, "Queremos ver Jesus", que busca traduzir na prática as Diretrizes da Ação Evangelizadora da Igreja no Brasil (2003-06) (24). Há uma grande preocupação com o êxodo de fiéis para outras confissões religiosas, em particular as denominações pentecostais, mas também com o desligamento de muitos jovens, que no último censo ampliaram as fileiras dos "sem religião" (25).

Nesse bloco mais amplo do catolicismo oficial, há baterias que buscam incentivar uma presença pública mais definida da Igreja Católica na sociedade, com o incentivo de projetos pastorais mais voltados para o social, como o Grito dos Excluídos, o Mutirão Nacional contra a Fome e a Exclusão, o Plebiscito da Dívida Externa e demais iniciativas relacionadas às Pastorais Sociais e à Campanha da Fraternidade. Mas não há dúvida de que essa presença no espaço público é distinta daquela exercida nos anos 70 e 80, quando a Igreja oficial e a CNBB em particular evidenciaram o rosto de uma igreja comprometida com o povo e os pobres. Essa situação foi se modificando à medida que o processo de restauração romana, de centralização e uniformidade, foi se afirmando em âmbito mais geral, provocando crescentes dificuldades, incompreensões e barreiras na atuação crítica da Igreja Católica no Brasil. Hoje, como avalia Brenda Carranza, predomina no catolicismo oficial certa sensação de instabilidade, debatendo-se

"[...] com as conseqüências dos modelos geográficos de paróquias, os quais se tornaram obsoletos, se comparados à mobilidade que as afinidades eletivas dos fiéis produzem, pois na procura de experiências religiosas e participação sacramental os paroquianos se tornam desterritorializados. Às vezes atônito com os dados estatísticos da evidente migração religiosa, e às vezes animado com o arrebanhamento de fiéis em encontros multitudinários, o bloco institucional sofre as pressões da reinstitucionalização romanizada presente em suas fileiras, sejam padres ou bispos, sejam leigos ou religiosos. No centro da avenida esse catolicismo avança no ritmo dois pra frente, um pra trás” (26).

Seguindo a pista aberta por Danièle Hervieu-Léger, a situação de mobilidade, típica de uma modernidade religiosa tecida pelas experiências pessoais, favorece a emergência de uma outra figura na paisagem das religiões, que é a do convertido. Trata-se de uma figura que se encaixa bem para exemplificar a afirmação identitária presente em algumas experiências religiosas em curso no Brasil, como a Renovação Carismática Católica (RCC) e as Comunidades Eclesiais de Base (CEBs). A conversão vem aqui entendida não como mudança de religião ou inserção religiosa de pessoas que jamais pertenceram a qualquer outra tradição, mas de "refiliação" religiosa. É uma experiência que envolve pessoas que descobrem ou redescobrem uma identidade religiosa até então vivenciada superficialmente, e que traduz a 
serem-se num projeto eclesial tipicamente moderno. Essas comunidades eclesiais

“[...] se instituem no meio popular como um espaço social produtor de uma nova inteligibilidade da experiência religiosa. Uma experiência que ganha plausibilidade na medida em que consegue inscrever as práticas sociais e políticas no âmbito religioso, de forma que a consciência apareça como acesso privilegiado ao sagrado" (34).

Em razão dessa "modernidade sistêmica” presente nas CEBs, ocorreram tensões e embates com o catolicismo popular, seja mediante a assunção de uma linguagem racionalizadora que descarta a linguagem popular tradicional, seja na instrumentalização da religião popular, valorizada unicamente como espaço para o exercício da conscientização. Isso ocorreu sobretudo no momento mais inicial da experiência das CEBs. Posteriormente, aproximações mais salutares foram realizadas (35).

As CEBs viveram o seu momento de maior efervescência nas décadas de 70 e 80 , envolvendo distintas formas de pertencimento (36). A partir do final dos anos 80 , com os novos ventos da conjuntura eclesiástica internacional, elas encontram inúmeras resistências e mesmo impedimentos para a continuidade de sua afirmação criadora. Mas sobrevivem à crise e ampliam o campo de seu interesse para novos desafios, como os da cultura, etnia, gênero, subjetividade, ecologia, espiritualidade, ecumenismo e diálogo inter-religioso.

Na visão de Luiz Alberto Gómez de Souza, seria simplificador concluir de forma apressada, como tendem a fazer hoje certos analistas, que o momento atual marca a vitalidade de novos movimentos eclesiais, e em particular da RCC, e o recuo das CEBs. Em sua visão, "se o movimento carismático aumenta, isso não indica que as pastorais sociais e as CEBs declinem" (37). Os três últimos intereclesiais de CEBs, ocorridos em São Luís (1997), Ilhéus (2000) e Itabira (2005), e pesquisas de campo apontam a vitalidade da experiência, ainda que com novas nuances, e a presença cada dia mais renovada de uma sensibilidade ecumênica e inter-religiosa (38).

Um importante fenômeno emergente no campo religioso brasileiro é o do $\mathrm{ca}$ tolicismo midiático (39), que se encontra relacionado com a diversificação da experiência da Renovação Carismática Católica. Essa nova malha católica envolve "diversas práticas e grupos religiosos que podem ser aglutinados sob o imenso guarda-chuva chamado Renovação Carismática Católica que, junto a outros setores eclesiásticos, implementaram um outro jeito de ser Igreja" (40). É sobretudo em razão de sua presença nos meios de comunicação de massa que a RCC marcou uma nova atuação pública na sociedade brasileira. Esses meios de comunicação foram também os instrumentos privilegiados que ela encontrou para fazer frente ao progressivo processo de “destradicionalização" em curso na sociedade brasileira e apostar na reinstitucionalização católica.

Um dos grandes destaques desse catolicismo midiático é o padre Marcelo Rossi, que teve sua rápida ascensão na mídia no final de 1998. Sua presença tem sido contante nos diversos meios de comunicação social e, em particular, na Rede Globo de Televisão. Além de fazer grande sucesso na rádio e $\mathrm{TV}$, é também fenômeno discográfico, com importantes registros na vendagem de CDs voltados para a evangelização católica, bem como um fenômeno cinematográfico e também editorial (41). Mas o catolicismo midiático conta também com outros personagens, como o padre Jonas Abib, padre Antônio Maria, padre Joãozinho e padre Jorjão. Há que ressaltar no quadro desse novo catolicismo a afirmação de novas redes de televisão voltadas para a evangelização, como a Canção Nova, a Rede Vida a Século XXI. Merece destaque a Canção Nova, que foi adquirida pelos membros da comunidade de vida Canção Nova(42) em 1980, inaugurandoem 1989 a primeira transmissora de televisão. Nasceu como um canal privilegiado para a missão evangelizadora e mantém ainda hoje esta função primordial, mas numa linha marcada por forte tom apologético.

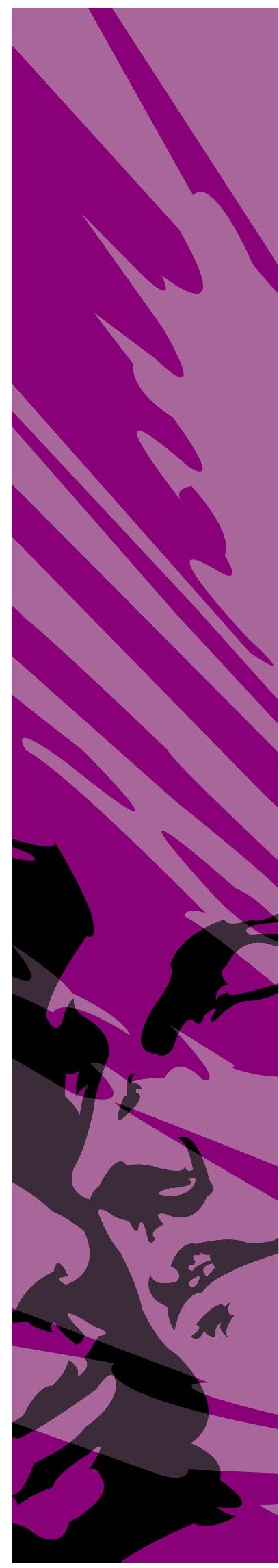




\section{CONCLUINDO}

Depois de passar brevemente pelas distintas malhas do catolicismo brasileiro, pode-se retomar a questão levantada no início a partir de uma indagação polêmica de Antônio Flávio Pierucci sobre a pretensa diversidade religiosa no Brasil. Um olhar exclusivo para a declaração de crença do último censo espelha, de fato, uma diversidade "rala, apertada" e "rarefeita", concentrada na sobra dos $3,5 \%$ de declarantes que não são católicos, evangélicos ou “sem religião". Mas o olhar atento para as práticas e crenças reais favorece perceber outras vertentes que escapam aos dados quantitativos. O que se vê, como no caso do catolicismo majoritário, é a presença de uma identidade plástica, permeável ao influxo de outras tradições e sistemas religiosos, ou, pelo menos, de seus fragmentos. $\mathrm{E}$ isso ocorre inclusive em expressões religiosas com propostas de exclusivismo religioso, como é o caso da RCC. Tudo isso é surpreendente e dá razão a Pierre Sanchis quando fala da "encruzilhada" que é o catolicismo, de sua pluralidade inusitada: uma religião que envolve muitas religiões. O pluralismo religioso se expressa nas frestas de uma pretensa homogeneidade; ele brilha na "metamorfose das práticas e crenças reelaboradas" ou reinventadas. Não há dúvida, este é um país de sincretismo religioso e de intenso trânsito entre tradições que aparentemente se opõem, mas que de forma enigmática deixam no outro as marcas de sua tatuagem.

NOTAS

1 Cândido Procópio F. de Camargo, Católicos, Protestantes, Espíritas, Petrópolis, Vozes, 1973, p. 24.

2 Cesar Romero Jacob, Dora Rodrigues Hees; Philippe Waniez \&Violette Brustlein, Atlas da Filiação Religiosa e Indicadores Sociais no Brasil, Rio de Janeiro/São Paulo, PUC-Rio/Loyola/CNBB, 2003, p. 15

3 Pierres Sanchis, "O Repto Pentecostal à Cultura Católico-brasileira", in Alberto Antoniazzi et alii, Nem Anjos nem Demônios, Petrópolis, Vozes, 1994, p. 36 E em texto posterior confirma essa tendência: "A estatística revela um deslizar constante na direção de um irreversível declínio institucional do catolicismo" (Pierre Sanchis, "Religiões, Religião... Alguns Problemas do Sincretismo no Campo Religioso Brasileiro", in Alberto Antoniazzi (org.), Fiéis e Cidadãos. Percursos de Sincretismo no Brasil, Rio de Janeiro, Edueri, 2001, p. 11.

4 Antônio Flávio Pierucci, "Cadê Nossa Diversidade Religiosa?", 2005, mimeo. Praticamente todos os textos indicados como mimeo. nas notas estão para ser publicados em livro organizado por Faustino Teixeira e Renata Menezes sobre o Campo Religioso Brasileiro: Continuidades e Rupturas. Trata-se de textos que foram apresentados, numa primeira versão, em seminário organizado pelo Iser/Assessoria em Juiz de Fora em agosto de 2004.

5 Pierre Sanchis, "Introdução", in P. Sanchis (org.), Catolicismo: Modernidade e Tradição, São Paulo, Loyola, 1992, p. 33.

6 Carlos Rodrigues Brandão, "Fronteira da Fé - Alguns Sistemas de Sentido, Crenças e Religiões no Brasil de Hoje", in Estudos Avançados, v. 18, n. 52 , 2004, p. 282 (Dossiê Religiōes no Brasil).

7 Os autores do Atlas da Filiação Religiosa mostram-se surpresos com o reduzido número de pessoas que no Censo de 2000 declararam pertencer a mais de uma religião (apenas 10.500 pessoas), e levantam a hipótese de que "os recenseados ainda não se sentem à vontade para assumir que possuem mais de uma filiação religiosa" (Cesar Romero Jacob et alii, Atlas da Filiação Religiosa e Indicadores Sociais no Brasil, op. cit., p. 9).

8 Carlos Rodrigues Brandão, "Ser Católico: Dimensões Brasileiras. Um Estudo sobre a Arribuição da Religião", in Rubem César Fernandes et alii, Brasil \& EUA. Religião e Identidade Nacional, Rio de Janeiro, Graal, 1988, p. 50. Conforme Brandão (1988, p. 51), "ser apenas católico significa haver sido incorporado por tradiçōes familiares e, depois, por um difuso costume pessoal a uma religião de que se reconhece sendo sem o envolvimento de quem se afirma praticando".

9 Roberto Da Matta, O que Faz o Brasil Brasil, Rio de Janeiro, Rocco, 1986, p. 115; Cecilia Mariz \& Maria das Dores C. Machado, "Sincretismo e Trânsito Religioso: Comparando Carismáticos e Pentecostais", in Comunicaçōes do Iser, v. 13, n. 45, 1994, p. 27.

10 João Guimarães Rosa, Grande Sertão: Veredas, 14ạ ed., Rio de Janeiro, José Olympio, 1980, p. 15

11 Cândido Procópio F. de Camargo, Católicos, Protestantes, Espiritas, op. cit., p. 32.

12 Francisco Cartaxo Rolim, "Condicionamentos Sociais do Catolicismo Popular", in Revista Eclesiástica Brasileira, v. 36, n. 141, 1976, p. 159. Ver ainda: Rubem César Fernandes, "Pouco Padre, Pouca Missa e Muita Festa". Cf. hitp://www.mre.gov.br/cdbrasil/itamaraty/web/port/artecult/religiao/apresent/apresent.htm lacessado em 17/8/2005)

13 Carlos Rodrigues Brandão, Os Deuses do Povo, São Paulo, Brasiliense, 1980, pp. 125-6.

14 Idem, "Ser Całólico: Dimensões Brasileiras", op. cit., p. 268; Memória do Sagrado. Estudos de Religião e Ritual, São Paulo, Paulinas, 1985, pp. 33-4. E também: Duglas Teixeira Monteiro, Os Errantes do Novo Século, São Paulo, Duas Cidades, 1974, pp. 82 e 86-90; Rubem César Fernandes, Os Cavaleiros do Bom Jesus. Uma Introdução às Religiōes Populares, São Paulo, Brasiliense, 1982, p. 62.

15 Pedro A. Ribeiro de Oliveira, "Religiões Populares", in Jose Oscar Beozzo lorg.l, Curso de Verão Il, São Paulo, Paulinas, 1988, p. 121

16 Carlos Alberto Steil, O Serrão das Romarias. Um Estudo Antropológico sobre o Santuário de Bom Jesus da Lapa, Petrópolis, Vozes, 1996, p. 249 (noła 26 ) e p. 48. Em sua tese doutoral, a antropóloga Renata Menezes dedicou-se ao estudo da devoção aos santos num convento franciscano do Rio de Janeiro. 
Apontou em sua pesquisa de campo a dinâmica autônoma da devoção aos santos, apesar das tentativas de controle por parte dos padres, bem como a prática da "combinação das devoções", como forma de ampliação das formas de proteção. Cf. Renata de Castro Menezes, A Dinâmica do Sagrado. Rituais, Sociabilidade e Santidade num Convento do Rio de Janeiro, Rio de Janeiro, Relume Dumará, 2004, pp. 194, 200 e 202.

17 Como indica Marcelo Camurça, "dos dez estados com maior percentual de católicos, os seis primeiros: Piauí (95\%), Ceará (93\%), Paraíba (93\%), Alagoas (81\%), Sergipe (81,7\%), Rio Grande do Norte (81,7\%) são nordestinos" (Marcelo Ayres Camurça, "A Realidade das Religiões no Brasil no Censo do IBGE $-2000^{\prime \prime}, 2005$, p. 7, mimeo.)

18 Carlos Rodrigues Brandão, Memória do Sagrado, op. cit., pp. 32 e 146

19 ldem, "Crença e Identidade. Campo Religioso e Mudança Cultural", in Pierre Sanchis, Catolicismo: Unidade Religiosa e Pluralismo Cultural, São Paulo, Loyola, 1992, p. 51; Marcelo Ayres Camurça, "A Realidade das Religiões no Brasil no Censo do IBGE" , op. cit., p. 7.

20 Danièle Hervieu-Léger, Le Pèlerin et le Converti. La Religion en Mouvement, Paris, Flammarion, 1999, pp. 53 e 61 seg.

21 Idem, ibidem, pp. 89-118

22 Antônio Flávio Pierucci, "Bye Bye, Brasil - O Declínio das Religiões Tradicionais no Censo 2000", in Estudos Avançados, v. 18, n. 52, 2004 , p. 19.

23 Paula Monteiro \& Ronaldo R. M. de Almeida, "O Campo Religioso Brasileiro no Limiar do Século. Problemas e Perspectivas", in Henrique Rattner, Brasil no Limiar do Século XXI, São Paulo, Fapesp/Edusp, 2000, p. 330.

24 Em entrevista publicada no portal da CNBB, o secretário-geral desse organismo, Dom Odilo Pedro Scherer, abordou as várias situações no Brasil que vêm desafiando a missão evangelizadora, entre elas o êxodo de fiéis que buscam a resposta às indagações existenciais e religiosas fora da comunidade católica. Cf. hitp:// www.cnbb.org.br/index.php?op=pagina\&chaveid=1018 (acessado em 17/8/2005).

25 Os últimos censos vêm registrando que a segunda opção de declaração de crença entre os jovens vai para os "sem religião", que significa na prática a adesão a "formas não institucionais de espiritualidade que são normalmente classificadas como esotéricas, nova era, holísticas, de ecologia profunda". E a tendência da diminuição dos jovens que se declaram católicos acentua-se entre aqueles que se encontram na faixa etária de 15 a 24 anos /cf. Regina Novaes, "Os Jovens 'Sem Religião': Ventos Secularizantes, 'Espírito de Época' e Novos Sincretismos. Notas Preliminares", in Estudos Avançados, v. 18, n. 52,2004, pp. 321 e 3231.

26 Brenda Carranza, "Continuum Creativo: o Catolicismo Midiático", 2005, p. 8, mimeo.

27 Danièle Hervieu-léger, Le Pèlerin et le Converti, op. cit., pp. $119-29$

28 Carlos Alberto Steil, "Aparições Marianas Contemporâneas e Carismatismo Católico", in Pierre Sanchis (org.), Fiéis e Cidadãos, op. cit., p. 119; Eliane Martins de Oliveira, "'O Mergulho no Espírito Santo': Interfaces entre Catolicismo Carismático e a Nova Era lo Caso da Comunidade de Vida no Espírito Canção Noval", in Religião e Sociedade, v. 24, n. 1, 2004, p. 86

29 Cecília Loreto Mariz, "Catolicismo no Brasil Contemporâneo", 2005, p. 6, mimeo.

30 Eliane Martins de Oliveira, "O Mergulho no Espírito Santo", op. cit., pp. 85-6

31 Diversos autores têm hoje sublinhado o "fenômeno da impregnação espírita da sociedade brasileira", e as pesquisas vêm confirmando esse fato, por exemplo, na constatação da crença na reencarnação por parte de católicos praticantes (cf. Pierre Sanchis, "O Repto Pentecostal...", op. cit., p. 37).

32 Carlos Alberto Steil, "Renovação Carismática Católica: Porta de Entrada ou de Saída do Catolicismo?", in Religião e Sociedade, v. 24, n. 1, 2004, pp. 28-31; Eliane Martins de Oliveira, "O Mergulho no Espírito Santo", op. cit., pp. 96-8; Cecília Loreto Mariz, "Catolicismo no Brasil Contemporâneo", op. cit., p. 3. Carlos Steil vem sublinhando em recentes pesquisas a presença crescente de carismáticos católicos nos eventos das aparições marianas, um fenômeno que prolifera não só no Brasil, mas nos demais países de tradição católica (cf. Carlos Alberto Steil et alii, Maria Entre os Vivos. Reflexões Teóricas e Etnográficas sobre Aparições Marianas no Brasil, Porto Alegre, UFRGŚ Editora, 2003).

33 Carlos Alberto Steil, "Renovação Carismática Católica...", op. cit., p. 12. Esse autor levanta, assim, a hipótese de a RCC ser não apenas uma "porta de entrada para a lgreja Católica [...], mas também uma porta de saída, na medida em que liberaria seus fiéis para assumirem práticas e crenças que, em princípio, estão fora do sistema católico" (idem, ibidem, p. 28)

34 Carlos Alberto Steil, "CEBs e Catolicismo Popular", in Clodovis Boff et alii, As Comunidades de Base em Questão, São Paulo, Paulinas, 1997, p. 91 . E também: Faustino Teixeira, "A Espiritualidade nas CEBs", in Clodovis Boff et alii, As Comunidades de Base em Questão, op. cit., pp. 208-9.

35 Clodovis Boff, "CEBs: a que Ponto Estão e para Onde Vão?", in C. Boff et alii, As Comunidades de Base em Questão, op. cit., p. 285; Pedro A. Ribeiro de Oliveira et alii, Reforçando a Rede de uma Igreja Missionária. Avaliação Pastoral da Prelazia de São Felix do Araguaia, São Paulo, Paulinas, 1997, pp. 83-4.

36 Pedro Assis Ribeiro de Oliveira vai falar em "círculos concêntricos de pertencimento" envolvendo os praticantes (15\% a 30\%), os participantes (5\% a 10\%) e os animadores ou animadoras (1\% a 3\%). Círculos que se inserem numa massa maior de população católica, envolvendo cerca de $75 \%$ (cf. Pedro A. Ribeiro de Oliveira, "CEBs: Unidade Estruturante de Igreja", in Clodovis Boff et. alii, As Comunidades de Base em Questão, op. cit., pp. 145-6).

37 Luiz Alberto Gómez de Souza, "As Várias Faces da lgreja Católica", in Estudos Avançados, v. 18, n. 52, 2004 , p. 87.

38 Essa indicação de vitalidade foi igualmente apontada em recente pesquisa do Iser/Assessoria sobre o cotidiano das CEBs, realizada com quatro comunidades do estado do Rio e de Minas Gerais (cf. Ivo Lesbaupin et alii, As CEBs Hoje. Síntese de uma Pesquisa em Minas Gerais e Rio de Janeiro, Rio/São Leopoldo, Iser-Assessoria/Cebi, 2004, pp. 8 e 12). Constatou-se ainda, nessa mesma pesquisa, o influxo indireto exercido pela RCC sobre as CEBs no momento atual (idem, ibidem, pp. 33-4).

39 Trata-se de uma expressão utilizada pela socióloga Brenda Carranza.

40 Brenda Carranza, op. cit, p. 9

41 Idem, "Catolicismo em Movimento", in Religião \& Sociedade, v. 24, n. 1, 2004, pp. 126-9. Como assinala essa autora, o padre Marcelo Rossi "se apresenta como a imagem de uma lgreja rejuvenescida por meio de um sacerdote atleta, bonito, moderno, que inaugura Cyber-Cafés..." (idem, ibidem, p. 130).

42 As comunidades de aliança e vida relacionam-se com a RCC mas "não fazem parte da estrutura da RCC, ou seja, não são componentes que constituem a base ou a estrutura organizacional do movimento, como seriam os grupos de oração e outros órgãos de direção do movimento". Entre as comunidades de aliança e vida podem ser citadas a Canção Nova la mais antiga, sendo a primeira comunidade criada em 1978, na cidade de Queluz, SPI, a Toca de Assis (fundada em 1994, na cidade de Campinas) e a Shalom (fundada em 1982, no estado do Ceará) (ct. Cecília L. Mariz, "Comunidades de Via no Espírito Santo': um Novo Modelo de Família", s/d, mimeo.). Ver ainda: Antônio Mendes da C. Braga, "TV Canção Nova: 'Providência e Compromisso' x "Mercado e Consumismo'", in Religião \& Sociedade, v. 24, n. 1, 2004, pp. $113-23$. 